\title{
O AGRO NÃO É POP, NÃO É TECH, NÃO É TUDO: O PL N 6.299/2002 DO VENENO E O RETROCESSO SOCIOAMBIENTAL
}

\section{THE AGRO IS NOT POP, IT ISN'T TECH, IT IS NOT ALL: THE POISON DRAFT BILL (PL) NN 6.299/2002 AND THE SOCIAL ENVIRONMENTAL SETBACK}

\author{
LUIS GUSTAVO PATUZZI BORTONCELLO \\ Universidade de Itaúna (UIT) \\ luisbortoncello@gmail.com \\ DEILTON RIBEIRO BRASIL \\ Universidade de Itaúna (UIT) \\ deilton.ribeiro@terra.com.br
}

Fecha de recepción: 31 de julio de 2019 / Fecha de aceptación: 7 de enero de 2020

RESUMO: O estudo aborda a utilização de agrotóxicos na produção agrícola brasileira que corresponde a um dos pilares da economia brasileira. Um dos principais componentes desta produtividade é o emprego crescente de defensivos agrícolas que mantém o Brasil como um dos maiores produtores e exportadores de alimentos do mundo. Os impactos sobre o meio ambiente e na saúde do trabalhador e do consumidor são diversos e ainda incertos. Não obstante, no Congresso Nacional brasileiro encontra-se em tramitação o Projeto de Lei (PL) n 6.299/2002 denominado "Pacote do Veneno" que assume a primazia dos interesses do agronegócio no sentido de desmontar o já frágil sistema de controle de autorização, emprego e descarte de agrotóxicos em vigência no país. Conclui-se, ao final, que o $\mathrm{PL}$ infringe os princípios da prevenção, precaução e da vedação de retrocesso socioambiental. O risco às presentes e futuras gerações revela-se imediato. Os marcos constitucionais e legais, a partir de um estudo de caso sobre o impacto dos herbicidas hormonais nos cultivos da uva no Rio Grande do Sul, reforçam a incoerência da proposta. A pesquisa é de natureza teórico-bibliográfica seguindo o método indutivo que 
instruiu a análise da legislação, bem como a doutrina que informa os conceitos de ordem dogmática.

RESUMEN: El estudio aborda el uso de agroquímicos en la producción agrícola brasileña que corresponde a uno de los pilares de la economía brasileña. Uno de los principales componentes de esta productividad es el uso creciente de pesticidas que mantiene a Brasil como uno de los mayores productores y exportadores de alimentos del mundo. Los impactos en el medio ambiente y en la salud de los trabajadores y consumidores son dudosos y aún inciertos. Sin embargo, el Congreso Nacional de Brasil se encuentra actualmente en el curso del proyecto de ley (PL) No 6.299 / 2002 llamado "Paquete de Veneno" que asume la primacía de los intereses de los agro negocios para desmantelar el sistema ya frágil de control de autorización, empleo y disposición de agroquímicos vigentes en el país. Se concluye que el proyecto de ley $(P L) N^{\circ}$ 6.299 / 2002 contraviene a los principios de prevención, precaución y prohibición del retroceso social y ambiental. El riesgo para las generaciones presentes y futuras es inmediato. Los marcos constitucionales y legales, basados en un estudio de caso sobre el impacto de los herbicidas hormonales en el cultivo de la uva en Rio Grande do Sul, refuerzan la inconsistencia de la propuesta. La naturaleza de la investigación es teórica y bibliográfica siguiendo el método inductivo que instruyó el análisis de la legislación, así como la doctrina que informa los conceptos de orden dogmático.

RESUM: L'estudi aborda l'ús d'agroquímics en la producció agrícola brasilera, que correspon a un dels pilars de l'economia brasilera. Un dels components principals d'aquesta productivitat és l'ús creixent de pesticides, que manté el Brasil com un dels màxims productors i exportadors d'aliments del món. Els impactes en el medi ambient i en la salut dels treballadors i consumidors són dubtosos i encara incerts. No obstant això, el Congrés Nacional del Brasil es troba actualment en el curs del Projecte de llei (PL) núm. 6.299 / 2002 anomenat Paquet de Verí, que assumeix la primacia dels interessos dels agronegocis per desmantellar el sistema ja fràgil de control d'autorització, ús i disposició d'agroquímics vigents al país. Es conclou que el Projecte de llei (PL) núm. 6.299 
/ 2002 contravé als principis de prevenció, precaució i prohibició de la reculada social i ambiental. El risc per a les generacions presents i futures és immediat. Els marcs constitucionals i legals, basats en un estudi de cas sobre l'impacte dels herbicides hormonals en el cultiu del raïm a Rio Gran do Sul, reforcen la inconsistència de la proposta. La naturalesa de la recerca és teòrica i bibliogràfica seguint el mètode inductiu que va instruir l'anàlisi de la legislació, així com la doctrina que informa els conceptes d'ordre dogmàtic.

ABSTRACT: The study addresses the use of agrochemicals in Brazilian agricultural production that corresponds to one of the pillars of the Brazilian economy. One of the main components of this productivity is the growing use of pesticides that keeps Brazil as one of the largest food producers and exporters in the world. The impacts on the environment and in the worker and consumer health are doubtful and still uncertain. Nevertheless, the Brazilian National Congress is currently in the course of draft bill (PL) No 6.299/2002 called "Poison Package" that assumes the primacy of agribusiness interests in order to dismantle the already fragile system of control of authorization, employment and disposal of agrochemicals in effect in the country. It is concluded that the draft bill (PL) No 6.299/2002 is an offence against the principles of prevention, precaution and the prohibition of social and environmental setback. The risk to present and future generations is immediate. The constitutional and legal frameworks, based on a case study on the impact of hormonal herbicides on grape cultivation in Rio Grande do Sul, reinforce the inconsistency of the proposal. The research nature is theoretical and bibliographical following the inductive method that instructed the analysis of the legislation, as well as the doctrine that informs the concepts of dogmatic order.

PALAVRAS-CHAVE: Agrotóxicos; Projeto de Lei n 6.299/2002 - Danos ambientais - Impactos sobre a saúde do homem - Retrocesso socioambiental - Princípio da precaução - Princípio da prevenção. 
PALABRAS CLAVE: Agroquímicos — Proyecto de ley (PL) Nº 6.299 / 2002 — Daño ambiental - Impactos en la salud humana; Retroceso socioambiental — Principio de precaución - Principio de prevención.

PARAULES CLAU: Agroquímics - Projecte de llei (PL) núm. 6.299 / 2002 — dany ambiental - impactes en la salut humana — reculada socioambiental principi de precaució - principi de prevenció.

KEYWORDS: Agrochemicals; Draft bill (PL) No 6.299/2002 - Environmental harm - Impacts on human health - Social environmental setback Precautionary principle - Principle of prevention.

SUMÁRIO: I. Introdução. II. O impacto dos herbicidas hormonais nos cultivos sensíveis: o caso da uva no Rio Grande do Sul. III. O "PL do Veneno" e o retrocesso socioambiental. IV. A matriz legal e a proteção já (in)suficiente da Lei n 7.802/89. V. Considerações finais. VI. Referências.

\section{INTRODUÇÃO}

A produção agrícola pode ser afetada por diversas pragas como insetos, patógenos e plantas invasoras. Para combater estes organismos são empregados produtos químicos tais como inseticidas, fungicidas, acaricidas, nematicidas, bactericidas, vermífugos etc. Agrotóxicos são produtos químicos utilizados na agricultura com o objetivo de combater pragas e outros organismos patógenos que comprometem a produção agrícola. Contudo, a utilização maciça destes insumos é causa de contaminação ambiental além de prejudicar a saúde do trabalhador rural e do próprio consumidor.

Dos 50 agrotóxicos mais utilizados no país, 22 são vedados na Europa ${ }^{1}$. Além de campeão mundial no uso de agrotóxicos, o Brasil possui uma política extremamente permissiva para a liberação e uso de agrotóxicos. Além de campeão mundial no uso de agrotóxicos, o Brasil possui uma política

\footnotetext{
${ }^{1}$ DW BRASIL. Brasil ainda usa agrotóxicos já proibidos em outros países. Disponível em: http://www.dw.com/pt-br/brasil-ainda-usa-agrot\%C3\%B3xicos-j\%C3\%A1-proibidos-em-outrospa\%C3\%ADses/a-18837979. Acesso em: 20 jul. 2019.
} 
extremamente permissiva para a liberação e uso de agrotóxicos. Embora proibidos nos Estados Unidos e na Europa Ocidental, curioso que grande parte da produção agrícola brasileira - impregnada por "defensivos agrícolas" - tem nestas regiões grandes mercados compradores, revelando, portanto, a esquizofrenia que incide sobre o tema, embora ameaças de suspensão nas importações sejam frequentes ${ }^{2}$.

Aguarda apreciação no plenário do Senado Federal, após aprovação da Comissão Especial da Câmara dos Deputados, o PL n 6.299/02 - o "PL do Veneno" - proposto pelo Senador Blairo Maggi ${ }^{3}$, um dos maiores produtores mundiais de soja, que "altera os artigos $3^{\circ}$ e $9^{\circ}$ da Lei $n^{\circ} 7.802$, de 11 de julho de 1989, que dispõe sobre a pesquisa, a experimentação, a produção, a embalagem e rotulagem, o transporte, o armazenamento, a comercialização, a propaganda comercial, a utilização, a importação, a exportação, o destino final dos resíduos e embalagens, o registro, a classificação, o controle, a inspeção e a fiscalização de agrotóxicos, seus componentes e afins, e dá outras providências". O assunto é polêmico, tanto que tramita há mais de 15 anos e apensados a ele existem outros 29 projetos de lei.

A bancada ruralista, principal defensora da causa, justifica o projeto de lei para modernizar o setor, tornando a produção agrícola brasileira mais competitiva no mercado mundial. A posição, conforme o relator da matéria na Comissão Especial da Câmara dos Deputados, deputado Luiz Nishimori, é clara: “(...)

\footnotetext{
${ }^{2} \mathrm{O}$ impacto do uso de agrotóxicos sobre a saúde humana vem sendo tratado como uma das principais prioridades de toda a comunidade científica ao redor do planeta, particularmente nos países em desenvolvimento onde estes agentes químicos são amplamente utilizados na produção agrícola. Os países em desenvolvimento representam $30 \%$ de todo o mercado global consumidor de agrotóxicos, sendo o Brasil o maior mercado consumidor individual dentre estes países, equivalente à metade de todo o consumo da região latino-americana. $O$ uso indiscriminado de agrotóxicos no Brasil - assim como em outros países da América Latina resulta em níveis severos de poluição ambiental e intoxicação humana, uma vez que grande parte dos agricultores desconhecem os riscos a que se expõem e, consequentemente, negligenciam algumas normas básicas de saúde e segurança no trabalho. Alguns estudos que avaliaram a exposição ocupacional e ambiental a agrotóxicos no Brasil registraram índices de intoxicação que variam de $3 \%$ a $23 \%$ das populações estudadas. Se aplicarmos o menor percentual encontrado $(3 \%)$ ao número de trabalhadores rurais registrados no país aproximadamente 18 milhões, dados de 1996 - o número aproximado de indivíduos contaminados por agrotóxicos no desenvolvimento de atividades de trabalho no país seria de 540.000 trabalhadores ano, com 4.000 mortes (PERES; MOREIRA; LUZ, 2007, p. 4).

3 UOL. Blairo Maggi recebeu, do Greenpeace, o troféu "Motosserra de Ouro". Disponível em: http://noticias.uol.com.br/ultnot/2005/06/20/ult1928u1185.jhtm. Acesso em: 28 jul. 2019.
} 
estamos apresentando uma das melhores propostas para o consumidor, para a sociedade e para a agricultura, que precisa dos pesticidas como precisamos de

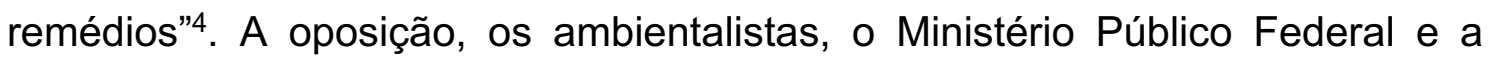
Defensoria Pública da União sustentam a inconstitucionalidade da proposta. Outros órgãos, como Ibama e Anvisa, também questionam o projeto de lei.

O discurso e as práticas vigentes no campo, de um modo generalizado, vem justificando o uso de agrotóxicos pela necessidade de uma "agricultura produtiva", sendo o país considerado, atualmente, o maior consumidor de agrotóxicos do mundo. O marco regulatório inicia verdadeiramente com a Lei $\mathrm{n}^{\circ}$ 7.802/89 que focou na pesquisa, experimentação, produção, utilização, destinação e resíduos dos agrotóxicos, primando pelo registro dos agrotóxicos, nos danos ao meio ambiente e à saúde pública. Posteriormente, a Lei $n^{\circ}$ 9.974/00 abordou a destinação das embalagens vazias de agrotóxicos, iniciativa melhor esmiuçada pelo Decreto $n^{\circ} 4.074 / 02$, que inseriu, dentre outras regulamentações, o conceito de centro ou central de recolhimento de embalagens vazias de agrotóxicos, finalizando, assim, o conceito de logística reversa na atividade.

$\mathrm{O}$ artigo é dividido em seis partes. A primeira parte é a introdução com destaque para a metodologia adotada no desenvolvimento da pesquisa. A segunda parte coloca em relevo algumas considerações necessárias sobre o impacto dos herbicidas hormonais nos cultivos sensíveis: o caso da uva no Rio Grande do Sul. O terceiro tópico é referente ao Projeto de Lei no 6.299/2002 denominado "Pacote do Veneno" e o retrocesso socioambiental. Em seguida, o quarto item trata sobre a matriz legal e a proteção já (in)suficiente da Lei $n^{0} 7.802 / 89$. Por último, no quinto tópico serão apresentadas as considerações finais sobre a temática colocada em relevo ao longo do trabalho bem como na sexta parte serão apresentadas as referências utilizadas no desenvolvimento da pesquisa.

\footnotetext{
${ }^{4}$ BRASIL. Câmara dos Deputados. Comissão especial aprova parecer que muda legislação brasileira sobre agrotóxicos. Disponível em: http://www2.camara.leg.br/camaranoticias/noticias/AGROPECUARIA/559559-COMISSAOESPECIAL-APROVA-PARECER-QUE-MUDA-LEGISLACAO-BRASILEIRA-SOBREAGROTOXICOS.html. Acesso em: 20 jul. 2019.
} 
O método utilizado para a realização do trabalho foi o indutivo com a abordagem de categorias consideradas fundamentais para o desenvolvimento nas perspectivas legal e ambiental sobre o tema da utilização dos agrotóxicos na agricultura e em especial sobre o PL 6.299/02 denominado "PL do Veneno" e seu impacto sobre o meio ambiente, a saúde do trabalhador e do consumidor que são diversos e ainda incertos Os procedimentos técnicos utilizados na pesquisa para coleta de dados foram essencialmente a pesquisa bibliográfica.

O levantamento bibliográfico forneceu as bases teóricas e doutrinárias a partir de livros e textos de autores de referência, tanto nacionais como estrangeiros. Enquanto o enquadramento bibliográfico utiliza-se da fundamentação dos autores sobre um assunto, o documental articula materiais que não receberam ainda um devido tratamento analítico. A fonte primeira da pesquisa é a bibliográfica que instruiu a análise da legislação constitucional e a infraconstitucional, bem como a doutrina que informa os conceitos de ordem dogmática.

Este artigo também se propõe apresentar um caso ocorrido no Rio Grande do Sul e, a partir dele, analisar o retrocesso ambiental representado pelo " $P L$ do Veneno", o desmonte do atual e frágil sistema de regulação e os impactos estimados no meio ambiente natural.

\section{O IMPACTO DOS HERBICIDAS HORMONAIS NOS CULTIVOS SENSÍVEIS: O CASO DA UVA NO RIO GRANDE DO SUL}

$\mathrm{Na}$ Campanha gaúcha intensifica-se o plantio de culturas sensíveis como videira, oliva, hortaliças, maçã e citros. Embora não ocupem o topo na produção econômica estadual, tais cultivos empregam mais mão de obra direta e indireta e representam importante atividade na diversificação da economia local, gerando opções, inclusive, no turismo e no ecoturismo. Contudo, nos últimos anos os produtores passaram a perceber prejuízos nas safras, tanto na qualidade quanto na quantidade do produto. Após pesquisas, vistorias e visitas técnicas, descobriu-se que o emprego de um herbicida nas lavouras de soja é o causador 
destes prejuízos. O estudo técnico que fundamenta este capítulo consiste, talvez, no primeiro documento que comprova que uma técnica do agronegócio que antes só afetava o meio socioambiental - passou a causar prejuízo no próprio agronegócio.

A partir de denúncias formuladas aos fiscais agropecuários do Rio Grande do Sul por produtores rurais de cultivos sensíveis aos herbicidas hormonais, como fruticultores, viticultores e hortaliças, a Secretaria de Agricultura, Pecuária e Desenvolvimento Rural gaúcha elaborou relatório técnico a partir vistorias, coletas e pesquisas de campo ${ }^{5}$. Em 2015, em reunião com os produtores rurais do município de Jaguari, os fiscais da respectiva pasta tiveram acesso aos primeiros relatos de problema de deriva do herbicida 2,4-D. No final de 2017, a Inspetoria de Defesa Agropecuária de Dom Pedrito começou a receber denúncias de deriva de agrotóxicos, supostamente 0 ácido 2,4diclorofenoxiacético (2,4-D) na região da Campanha. Ao longo de 2018 ocorreram reuniões técnicas e audiências públicas na região com o objetivo de orientar e conscientizar o uso de agrotóxicos, em especial sobre os cuidados a serem tomados no manuseio de herbicidas hormonais em áreas de cultivos sensíveis. No mesmo ano, laudos químicos comprovaram a presença do princípio ativo do 2,4-D nos cultivos sensíveis.

O princípio ativo 2,4-D possui mais de 70 anos de atuação no mercado e 40 mil estudos realizados por diferentes instituições de pesquisa. Contudo, são escassos os estudos referentes à deriva do 2,4-D, ou seja, há deficiência no conhecimento científico no que tange à possível definição de zonas de exclusão por causa da indefinição das distâncias máximas que o referido agrotóxico pode deslocar em virtude de deriva. Os próprios estudos da deriva, concluiu o relatório, não avaliaram o impacto em cultivos sensíveis ${ }^{6}$. Nos laudos elaborados pela

\footnotetext{
${ }^{5}$ RIO GRANDE DO SUL. Secretaria da Agricultura, Pecuária e Desenvolvimento Rural. Relatório Técnico Impacto dos herbicidas hormonais nos cultivos sensíveis a estes herbicidas (2019). Disponível em: http://estado.rs.gov.br/agricultura-apresenta-propostas-para-uso-do-herbicida-24-d-no-rio-grande-do-sul. Acesso em: 20 jul. 2019.

6 OLIVEIRA JÚNIOR, Rubens S. et al.(2007, p. 35-40) avaliaram o efeito de subdoses de 2,4-D na produtividade de uva Itália e suscetibilidade da cultura. Os autores simularam derivas de $1 \%$ a 16\%, assumindo uma aplicação de $1 \mathrm{~L} / \mathrm{ha}$, equivalente a 670 gramas de IA/ha, em diferentes fases vegetativas. Para doses aplicadas no estágio de florescimento, o resíduo foi menor que
} 
Secretaria da Agricultura, Pecuária e Desenvolvimento Rural, todos os resultados com presença do princípio dativo do 2,4-D tiveram valores elevados e foram detectados em fases anteriores ao florescimento. Foram comuns, segundo os estudos, sintomas de alongamento de gavinhas, epinastia das folhas e deformação de ramos jovens e de folhas, clores entre as nervuras e necrose das pontas das gavinhas ${ }^{7}$.

Das 82 análises realizadas sobre cultivos sensíveis, 67 apresentaram o princípio ativo 2,4-D, representando incríveis $83,8 \%$ de contaminação por deriva. Impressiona o fato de que, mesmo em propriedades rurais onde não havia lindeiro (cerca a cerca) com cultivo de soja, foi identificada a contaminação por deriva, comprovando o deslocamento das gotículas do herbicida de áreas mais afastadas. Também foi comprovada a contaminação em propriedades que tinham barreira vegetal ou quebra-ventos, sendo esta barreira natural (mato nativo) ou ainda outra espécie vegetal. Não bastasse isso, foram identificados sintomas de fitotoxidade em árvores do meio urbano, como na espécie de cinamomo (Meliaazedarach), no município de Santana do Livramento/RS ${ }^{8}$.

Pesquisadores da Embrapa já apresentaram alternativas ao uso do 2,4-D a partir de opções de herbicidas com diferentes mecanismos de ação, permitindo manejar e prevenir a resistência, embora com maior custo financeiro. Contudo, além da eficiência de controle, a utilização do 2,4-D tem demonstrado bom resultado econômico. Uma das preocupações dos sojicultores brasileiros seria a retirada do produto do mercado - o que provocaria um aumento significativo no custo para a produção de soja (aproximadamente US\$10,00/ha) ${ }^{9}$.

$0,010 \mathrm{mg} / \mathrm{kg}$ na uva colhida, embora tenha gerado dano econômico, com redução de $84,75 \%$ a $96,03 \%$ na produtividade.

7 Uma das possibilidades de controle cogitadas foi a criação de "zonas de exclusão", que acabou descartada em razão da ausência de marco regulatório específico, fragilidade dos mecanismos de controle e absoluta ausência de recursos humanos e materiais dos órgãos fiscalizadores. Para exemplificar, uma área de exclusão de $1 \mathrm{~km}$, a partir das videiras, acarretaria em 23.704 ha, equivalente a 23.704 campos de futebol, sendo que atualmente o órgão possui tão somente 5 fiscais de trabalho na região da Campanha. Ou seja, uma medida inócua.

${ }^{8}$ RIO GRANDE DO SUL. Secretaria da Agricultura, Pecuária e Desenvolvimento Rural. Relatório Técnico Impacto dos herbicidas hormonais nos cultivos sensíveis a estes herbicidas (2019). Disponível em: http://estado.rs.gov.br/agricultura-apresenta-propostas-para-uso-do-herbicida-24-d-no-rio-grande-do-sul. Acesso em: 20 jul. 2019.

${ }^{9}$ Segundo os pesquisadores da Embrapa, o custo médio com uso de 2,4-D foi de R\$ 8,58/ha. No caso de substituição o gasto médio com outros herbicidas foi de $R \$ 44,45 /$ ha, representando 
É nítido que os herbicidas hormonais, principalmente o 2,4-D, tem grande importância no manejo das plantas daninhas, principalmente aquelas que são resistentes ao glifosato. Contudo, não basta aplicar o agrotóxico. O manejo de plantas daninhas requer planejamento, com manejos de inverno e verão, com boas práticas agrícolas, manejo integrado, alternando o uso de herbicidas com diferentes princípios ativos com mecanismos de ação distintos, a fim de evitar resistência. O estudo concluiu, outrossim, que os danos causados pelo uso de 2,4-D no Rio Grande do Sul não estão restritos a pequenas áreas ou a uma região específica ${ }^{10}$.

Enquanto que a produção primária ganha a cada ano destaque na economia do Rio Grande do Sul (principalmente com grãos), representando fatia importantíssima do PIB, a diversificação na produção primária é fundamental no aspecto da sustentabilidade econômica, social e ambiental a partir de cultivos de oliveiras, nozes pecan, citros e outras frutíferas. Embora incipientes, os estudos comprovaram que, por conta do uso do 2,4-D, a diversificação da produção no Rio Grande do Sul tornar-se-á inviável por conta do cultivo da soja.

Em resumo, enquanto que o produtor de soja possui alternativa no combate às pragas, embora com custos mais elevados, o produtor de culturas sensíveis (videira, oliva, hortaliças, maçã, citros etc.) não tem como produzir e sofre diretamente os efeitos do emprego do referido herbicida em suas culturas. A Divisão de Inspeção de Produtos de Origem Vegetal da Secretaria da Agricultura, Pecuária e Desenvolvimento Rural do Rio Grande do Sul concluiu, também, que é improtelável a medida cautelar de suspensão do uso do 2,4-D no estado, sob pena de inviabilizar definitivamente pomares e agravar ainda mais 0 aspecto financeiro daqueles que vem acumulando perdas decorrentes das

um custo $418,07 \%$ maior. A opção econômica mais próxima seria o chlorimuron com $\mathrm{R} \$$ 13,60/ha, mas com algumas restrições sofre infestantes costumeiramente presentes nessa situação (RIO GRANDE DO SUL. Secretaria da Agricultura, Pecuária e Desenvolvimento Rural. Instrução Normativa SEAPDR $\mathrm{n}^{\circ}$ 05/2019. Disponível em: http://www.agricultura.rs.gov.br/agricultura-estabelece-regras-para-aplicacoes-de-agrotoxicospara-evitar-deriva. Acesso em: 20 jul. 2019).

10 RIO GRANDE DO SUL. Secretaria da Agricultura, Pecuária e Desenvolvimento Rural. Relatório Técnico Impacto dos herbicidas hormonais nos cultivos sensíveis a estes herbicidas (2019). Disponível em: http://estado.rs.gov.br/agricultura-apresenta-propostas-para-uso-doherbicida-2-4-d-no-rio-grande-do-sul. Acesso em: 20 jul. 2019. 
derivas. Além disso, o órgão sugeriu a estruturação da legislação estadual, com regras claras para a aplicação terrestre.

\section{O “PL DO VENENO” E O RETROCESSO SOCIOAMBIENTAL}

O princípio do Estado de Direito (nas suas diferentes dimensões) é um dos princípios fundamentais do constitucionalismo contemporâneo. Mas o Estado de Direito (aqui compreendido sempre como um Estado Democrático) assumiu e tem assumido diferentes configurações ao longo da evolução do constitucionalismo. Assim, tendo em conta os novos desafios gerados pela crise ecológica e pela sociedade tecnológica e industrial, a configuração de um novo modelo de Estado de Direito no horizonte jurídico-constitucional contemporâneo, superando os paradigmas antecedentes, respectivamente, do Estado Liberal e do Estado Social, passou a assumir um lugar de destaque.

A compreensão integrada e interdependente dos direitos sociais e da proteção do ambiente, mediante a formatação dos direitos fundamentais socioambientais, constitui um dos esteios da noção de desenvolvimento sustentável no âmbito do Estado Socioambiental de Direito ${ }^{11}$. Nesse sentido, José Afonso da Silva afirma que o desenvolvimento sustentável tem como seu requisito indispensável um crescimento econômico que envolva equitativa redistribuição dos resultados do processo produtivo e a erradicação da pobreza, de forma a reduzir as disparidades nos padrões de vida da população ${ }^{12}$.

$\mathrm{Na}$ configuração do atual Estado de Direito, a questão da segurança ambiental toma um papel central, assumindo o ente estatal a função de resguardar os cidadãos contra novas formas de violação da sua dignidade e dos seus direitos fundamentais por força do impacto socioambiental produzido pela sociedade de risco Ulrich Beck (2011) contemporânea. O Estado de Direito contemporâneo apresenta, de acordo com a lição de Canotilho, as seguintes dimensões

\footnotetext{
${ }^{11}$ SARLET, Ingo Wolfang; FENSTERSEIFER, Tiago. Princípios do direito ambiental. São Paulo: Saraiva, 2014, p. 29.

12 SILVA, José Afonso da. Direito ambiental constitucional. São Paulo: Malheiros Editores, 2003, p. 26-27.
} 
fundamentais, integradas entre si: juridicidade, democracia, sociabilidade e sustentabilidade ambiental ${ }^{13}$.

O princípio da solidariedade (expressão preferida à fraternidade) é resultado da Revolução Francesa para transformar-se no novo marco jurídico-constitucional dos direitos fundamentais de terceira dimensão (entre eles, o direito ao meio ambiente) e do Estado Socioambiental de Direito contemporâneo. O princípio da solidariedade, por certo, não opera de forma isolada no sistema normativo, mas atua juntamente com outros princípios e valores presentes na ordem jurídica, merecendo especial destaque para a justiça social, a igualdade substancial e a dignidade humana ${ }^{14}$. O comando constitucional expresso no artigo 225, caput, tem especial relevância para essa compreensão, pois traz justamente a ideia de responsabilidades e encargos ambientais compartilhados entre Estado e sociedade, quando subscreve que impõem "ao Poder Público e à coletividade o dever" de defender e proteger o ambiente para as presentes e futuras gerações, destacando que os deveres de solidariedade na tutela ambiental, para além do Estado, são atribuídos também aos particulares.

O Estado Socioambiental de Direito, longe de ser um Estado "Mínimo" (permissivo no que diz com o livre jogo dos atores econômicos e do mercado), deve ser um Estado regulador da atividade econômica, capaz de dirigi-la e ajustá-la aos valores e princípios constitucionais, objetivando o desenvolvimento humano e social de forma ambientalmente sustentável. O princípio do desenvolvimento sustentável expresso no artigo 170, VI, da Constituição Federal de 1988, confrontado com o direito de propriedade privada e a livre iniciativa (caput e inciso II do artigo 170), também se presta a desmitificar a perspectiva de um capitalismo liberal-individualista em favor dos valores e princípios constitucionais ambientais ${ }^{15}$.

\footnotetext{
13 CANOTINHO, Joaquim José Gomes. Estado de Direito. Cadernos Democráticos, $\mathrm{n}^{\circ} 7$, Fundação Mário Soares, Lisboa: Gradiva, 1998, p. 23.

14 SARLET, Ingo Wolfang; FENSTERSEIFER, Tiago. Princípios do direito ambiental. São Paulo: Saraiva, 2014, p. 70.

${ }^{15}$ Sobre a relação entre a Constituição Econômica, desenvolvimento e Constituição Dirigente, v., especialmente, BERCOVICI, Gilberto. Constituição Econômica e desenvolvimento..., 2005, p. 33 et seq. Propondo, com razão, a adoção de uma concepção constitucionalmente adequada e afinada com o estágio de desenvolvimento social, político, econômico e cultural dos países de modernidade tardia (países em desenvolvimento, habitualmente tidos como "periféricos"), v.
} 
A cláusula de progressividade atribuída aos direitos sociais deve abarcar, necessariamente, também as medidas fáticas e normativas voltadas à tutela ecológica, de modo a instituir uma progressiva melhoria da qualidade ambiental e, consequentemente, da qualidade de vida em geral. De tal sorte, é possível sustentar a ampliação da incidência do instituto da proibição de retrocesso para além dos direitos sociais, de modo a contemplar os direitos fundamentais em geral ${ }^{16}$, mais uma razão para levar a sério a crítica assacada por Jorge R. Novais, no sentido de que a metódica mais correta consiste em aplicar ao universo dos direitos fundamentais (incluindo, portanto, o direito ao ambiente) a teoria geral que dispõe sobre os limites e restrições dos direitos fundamentais, em vez de tratar os direitos sociais como se não fossem fundamentais ou mesmo constituíssem um grupo distinto a merecer uma tutela diferenciada ${ }^{17}$.

Assim, considerando que a proibição de retrocesso em matéria de proteção e promoção dos $\mathrm{DESCA}^{18}$ guarda relação com a previsão expressa de um dever de progressiva realização contido em cláusulas vinculativas de direito internacional, poder-se-á afirmar que pelo menos tanto quanto proteger o pouco que há em termo de direitos sociais e ecológicos efetivos, há que priorizar o dever de progressiva implantação de tais direitos. Com efeito, o progresso (em termos fáticos e normativos), aqui compreendido na perspectiva de um dever de desenvolvimento sustentável, necessariamente conciliando os eixos econômico, social e ambiental, segue sendo possivelmente o maior desafio não apenas, mas especialmente, para Estados Constitucionais tido como periféricos ou em fase de desenvolvimento.

A garantia da proibição de retrocessos (socio)ambiental ${ }^{19}$, nessa perspectiva, seria concebido no sentido de que a tutela jurídica ambiental - tanto sob a

STRECK, Lenio Luiz. Jurisdição constitucional e hermenêutica: uma nova crítica do Direito. Rio de Janeiro: Forense, 2003.

16 SARLET, Ingo Wolfang. A eficácia dos direitos fundamentais. Porto Alegre: Livraria do Advogado, 2009, p. 437.

17 NOVAIS, Jorge Reis. Direitos fundamentais: trunfos contra a maioria. Coimbra: Coimbra Editora, 2006, p. 196.

${ }^{18}$ Direitos econômicos, sociais, culturais e ambientais.

${ }^{19}$ Cabe destacar a expressão princípio da proibição de retrogradação socioambiental, difundida, entre nós, por MOLINARO, Carlos Alberto. Direito ambiental: proibição de retrocesso. Porto Alegre: Livraria do Advogado, 2007, na esteira da doutrina do professor alemão Michael Kloepfer. 
perspectiva constitucional quanto infraconstitucional - deve operar de modo progressivo no âmbito das relações socioambientais, a fim de ampliar a qualidade de vida existente hoje e atender a padrões cada vez mais rigorosos de tutela da dignidade da pessoa humana, não admitindo o retrocesso, em termos fáticos e normativos, a um nível de proteção inferior àquele verificado hoje ${ }^{20}$. A liberdade política do legislador em matéria de política ambiental possui menos espaço no que tange à reversibilidade político-jurídica da proteção socioambiental, sendo-lhe vedado criar novas normas que importam em retrocesso das posições jurídico-ambientais já enraizadas.

Na medida em que a proibição de retrocesso socioambiental se coloca como "blindagem protetiva" em face da atuação dos poderes públicos, no âmbito das suas funções legislativa, administrativa e judiciária, pode-se conceber a sua incidência sobre a própria estrutura administrativa e organizacional do Estado voltado à promoção de determinado direito fundamental. Em época sinistra, onde $1 / 4$ da bancada do Congresso Nacional possui estreita vinculação com 0 agronegócio, onde o Governo Federal empodera a Agricultura e faz questão de enfraquecer o Meio Ambiente, cabe destacar que determinado ato administrativo que culminasse por reduzir em demasia a estrutura administrativa hoje existente para a tutela ecológica (enxugamento ou mesmo extinção do Ibama sem a criação de órgão ambiental equivalente), impossibilitando a fiscalização e a adoção de políticas públicas ambientais de modo minimamente suficientes para salvaguardar tal direito fundamental, estaria por violar a proibição de retrocesso socioambiental (além da proibição da proteção insuficiente) e a medida administrativa em questão estaria eivada de inconstitucionalidade ${ }^{21}$.

Para finalizar o marco regulatório principiológico-constitucional não se pode esquecer dos princípios da prevenção e da precaução. O princípio da prevenção é um dos mais característicos do direito ambiental, além de ser um dos mais "antigos". Ele transporta a ideia de um conhecimento completo sobre os efeitos de determinada técnica e, em razão do potencial lesivo já diagnosticado, o

\footnotetext{
${ }^{20}$ SARLET, Ingo Wolfang; FENSTERSEIFER, Tiago. Princípios do direito ambiental. São Paulo: Saraiva, 2014, p. 194-195.

${ }^{21}$ Id. Ibidem, 2014, p. 199.
} 
comando normativo toma o rumo de evitar tais danos já conhecidos. Diante da iminência de uma atuação humana que comprovadamente lesará de forma grave e irreversível bens ambientais, tal intervenção deve ser coibida. Já o princípio da precaução, por sua vez, tem um horizonte mais abrangente, pois objetiva regular o uso de técnicas sob as quais não há um domínio seguro dos seus efeitos. É o agir prevenindo em caso de incerteza, não se aguardando que esta se torne certeza (e possivelmente danosa ao meio ambiente e ao homem).

\section{A MATRIZ LEGAL E A PROTEÇÃO JÁ (IN)SUFICIENTE DA LEI No 7.802/89}

Órgãos técnicos como Anvisa e lbama - que desempenham papel fundamental no controle de agrotóxicos - possuem dezenas de notas técnicas criticando o "PL do Veneno". Antes de adentrar para a matriz legal propriamente dita, é necessário frisar que o PL em questão usa a semântica como forma de ludibriar o consumidor e o dever de informação, uma vez que propõe a eliminação da denominação "agrotóxico", o que já configura inconstitucionalidade em razão do disposto no artigo $220, \S 4^{\circ}$, da Constituição Federal de 1988: "a propaganda comercial de tabaco, bebidas alcoólicas, agrotóxicos, medicamentos e terapias estará sujeita a restrições legais, nos termos do inciso II do parágrafo anterior, e conterá, sempre que necessário, advertência sobre os malefícios decorrentes de seu uso" (Grifo nosso).

A intenção do constituinte é óbvia; garantir proteção ao consumidor contra produtos tóxicos, nocivos, tais como o tabaco, as bebidas alcoólicas e os agrotóxicos. A substituição do nome agrotóxico por "defensivos fitossanitários" ou mesmo "pesticidas" viola essa intenção protetiva disposta na Constituição, podendo dar ao consumidor a ideia de que ele está consumindo um produto de menor toxidade, apesar de a mudança ter sido apenas de nomenclatura ${ }^{22}$. Esta, infelizmente, é das alterações de menor impacto.

22 VIEGAS, Eduardo. Os danos potenciais com a aprovação do PL do Veneno. Disponível em: http://www.conjur.com.br/2018-jul-21/ambiente-juridico-danos-potenciais-aprovacao-pl-veneno. Acesso em: 26 jul. 2019. 
A Lei $n^{0} 7.802 / 89$ estabelece minimamente regras protetivas à saúde e ao meio ambiente e proíbe o registro de agrotóxicos, seus componentes e afins que revelem características teratogênicas, carcinogênicas ou mutagênicas, de acordo com os resultados atualizados de experiências da comunidade científica. O "PL do Veneno", por sua vez, substitui tal norma pela seguinte, in verbis:

Fica proibido o registro de produtos fitossanitários, de produtos de controle ambiental e afins que, nas condições recomendadas de uso, apresentem risco inaceitável para os seres humanos ou para o meio ambiente, ou seja, permanece inseguro mesmo com a implementação das medidas de gestão de risco (Grifo nosso).

O retrocesso socioambiental desta norma é cristalino. Não bastasse isso, apresentar risco inaceitável afronta, outrossim, o princípio da prevenção ou da precaução e, por si só, revela-se inconstitucional.

No panorama atual, cabe à Anvisa realizar a análise e a avaliação do risco. Primeiro, identifica-se o perigo e, caso se verifique que há indicativo de efeito nocivo, o produto não tem seu uso autorizado no Brasil. Logo, verificado que não afeta a saúde humana, passa-se às demais etapas da avaliação do agrotóxico. O "PL do Veneno", em contrapartida, substitui a análise de risco pela análise de perigo, pois se o risco for "aceitável" o produto poderá ser registrado, comercializado e aplicado nas lavouras brasileiras.

De acordo com a Lei n 7.802 de 1989, um agrotóxico associado a qualquer um desses efeitos é indicado para proibição. O PL prevê a revogação desse artigo e, consequentemente permitir o registro de produtos com esse potencialdesde que o risco seja considerado "aceitável". O cálculo do "risco aceitável" se dá basicamente por meio da definição de doses nas quais esses efeitos, em tese, não se manifestariam. O que ocorre é que para muitos desses efeitos não é possível definir um limite de segurança. Isso porque vários deles ocorrem em condições de exposição a quantidades muito pequenas, como as presentes na água, nos alimentos, no ar, poderiam resultar em doenças graves, como o câncer por exemplo. 
Não bastasse isso, a insegurança deliberada do $\mathrm{PL}$ afeta diretamente os prazos de avaliação do produto ao estabelecer que os pedidos de registro e suas alterações deverão ocorrer, em relação aos produtos novos, em 12 meses; e, para as demais alterações, minguados 180 dias, sob pena de imposição e responsabilidade aos agentes responsáveis pelos estudos. Na maioria dos casos, a Anvisa depende de informações de outros órgãos ou do próprio fabricante para finalizar a análise, sem contar que tais prazos extremamente diminutos, considerando-se os efeitos nocivos do "defensivo" em questão, podem colocar o meio ambiente e o homem em severo risco.

Em termos práticos, o "PL do veneno" pretende acelerar o registro de produtos agrotóxicos, eliminando a exigência de um processo de avaliação acurado dos estudos toxicológicos. Tais estudos são experimentos realizados com animais de laboratório como ratos, camundongos, coelhos e outros nos quais se testam os efeitos que podem vir ao correr quando um ser humano entra em contato com o agrotóxico. No entanto, o que é testado é o ingrediente ativo (princípio ativo) do agrotóxico, na sua forma mais pura. Os resultados desses testes são apresentados pelas indústrias e a Anvisa que os avalia para determinar se é possível registrar o agrotóxico ou não, com base nos efeitos sobre a saúde humana. O atual quadro, por si só, já é insuficiente, uma vez que a Anvisa realiza suas análises em informações prestadas pelo próprio fabricante/interessado.

Ainda no que tange à irresponsabilidade no registro de agrotóxicos, o "PL do Veneno" traz a figura do "registro temporário". Para os produtos que estejam registrados para culturas similares em pelo menos 3 dos 37 países-membros da Organização para Cooperação e Desenvolvimento Econômico (que adotam, nos respectivos âmbitos, o Código Internacional de Conduta sobre a Distribuição e Uso de Pesticidas da FAO), a nova legislação reserva o registro temporário, um verdadeiro atalho que coloca o produto desde já na lavoura brasileira, cabendo aos órgãos responsáveis uma análise a posteriori da nocividade do agrotóxico. E como destaca a Fiocruz, a situação do produto em um ou alguns países pode variar totalmente de quando é introduzido em outro. Sua toxidade é influenciada por diversos fatores, além das propriedades físico-químicas e cinéticas comuns aos agrotóxicos. Como destaca a Fiocruz em sua nota técnica sobre o PL, 
características genéticas, socioculturais, epidemiológicas e edafoclimáticas, por exemplo, interferem diretamente na toxidade e variam entre os países ${ }^{23}$.

O registro temporário poderá gerar danos irreparáveis ou de difícil reparação, uma vez que poderá ser necessário o transcurso de bons anos para o meio ambiente ou o homem poderão acusar que a toxidade de determinado agrotóxico deve impedir seu emprego no país.

O que o PL define como "desburocratização" é, em última instância, a redução do tempo para analisar estes resultados, a criação de dificuldades para que novos estudos sejam solicitados (o que é importante para muitos casos onde há dúvida sobre a segurança do produto para seres humanos) e, em algumas situações, a previsão de que os estudos sequer precisem ser apresentados pela indústria. De fato, a solução mais eficaz e segura seria investir - técnica, materialmente e em pessoal - nos órgãos responsáveis pelo registro e em uma rede pública de laboratórios credenciados para suporte especializado.

O PL abre ainda outra prerrogativa extremamente preocupante ao estabelecer o tempo máximo de um ano para análise dos estudos (toxicológicos, ambientais) para o registro. Caso a análise não seja realizada até encerrado o prazo, o agrotóxico poderá entrar no Brasil mesmo sem a anuência do órgão responsável, apenas tendo como base o parecer de outros países da OCDE (que não necessariamente tenham as mesmas características ambientais, nutricionais e de vida do Brasil).

Nesse sentido, como aponta o Ibama no seu parecer técnico sobre o PL,"não há isonomia na decisão entre a aprovação e restrição, pois o "Substitutivo"não trata dos casos de proibição em outros países"24. Seguindo esta lógica, deveria caber uma proibição imediata de agrotóxicos no Brasil, assim que houvesse a sua

${ }^{23}$ BRASIL. Ministério da Saúde. Fiocruz divulga nota técnica contra projeto que flexibiliza regulação de agrotóxicos. Disponível em: http://portal.fiocruz.br/sites/portal.fiocruz.br/files/documentos/nota_tecnica_pl_agratoxicos.pdf. Acesso em: 27 jul. 2019.

${ }^{24}$ BRASIL. Instituto brasileiro do meio ambiente e dos recursos naturais renováveis - Ibama. Nota técnica $\quad n^{\circ} \quad 4 / 2018 / D I Q U A$ Disponível em: http://www.ibama.gov.br/phocadownload/notas/2018/nota_tecnica_4_2018_diqua.pdf. Acesso em: 26 jul. 2019. 
proibição em outros países por conta dos seus impactos sobre a saúde e ou ambiente, proposta esta não feita no PL nº 6.299.

O "PL do Veneno" inova, também, ao romper com o sistema de avaliação tripartite para a concessão de registro de agrotóxicos no país. Atualmente, a autorização estatal para emprego do agrotóxico depende de manifestação favorável do Ministério da Saúde, do Ministério do Meio Ambiente (MMA) e do Ministério da Agricultura, Pecuária e Abastecimento (MAPA). No Ministério da Saúde, a Anvisa é responsável por avaliar a toxidade e efeitos do produto à saúde humana. No MMA, o Ibama realiza a avaliação ecotoxicológica. Por fim, no Mapa é realizada a avaliação de eficácia agronômica. Porém, a alteração legal prevê que o órgão federal responsável pelo setor da agricultura será o registrante único dos produtos fitossanitários e afins ${ }^{25}$.

Conforme a nota técnica da Anvisa, a proposta é que não haja mais avaliação e classificação de produtos pela área da saúde e meio-ambiente, mas apenas uma 'homologação' da avaliação realizada pelas empresas registrantes. Conclui a referida agência que essa proposta claramente desconsidera a responsabilidade e dever do Estado em reduzir, por meio de políticas públicas, o potencial de dano à saúde oriundo da exposição a agrotóxicos e afins ${ }^{26}$.

Como não podia ser diferente, o lbama sustenta que as modificações introduzidas diminuem as garantias para a defesa e proteção à saúde e ao meio ambiente em prol do interesse econômico. Segundo este órgão ambiental, a função homologatória atribuída aos órgãos públicos federais relativamente ao que for apresentado pela iniciativa privada interessada no registro de agrotóxicos depõe contra o interesse público e a indelegabilidade do poder de polícia atribuído ao setor regulado. Não pode o Estado renunciar aos seus mecanismos de avaliação e controle prévio de substâncias nocivas ao meio ambiente,

${ }^{25}$ VIEGAS, Eduardo. Os danos potenciais com a aprovação do PL do Veneno. Disponível em: http://www.conjur.com.br/2018-jul-21/ambiente-juridico-danos-potenciais-aprovacao-pl-veneno. Acesso em 26 jul. 2019.

${ }^{26}$ BRASIL. Agência Nacional de Vigilância Sanitária - ANVISA. Nota Técnica $\mathrm{n}^{\circ}$ 15/2018/SEI/DICOL/ANVISA. Disponível em: http://portal.anvisa.gov.br/documents/219201/4340788/_+SEl+_+ANVISA+-+0202694++Nota+T\%C3\%A9cnica+da+Dicol+__.pdf/7af8b109-5fbe-4338-b5fa-3698e513bf96. Acesso em: 26 jul. 2019. 
contentando-se apenas com o ato homologatório de uma avaliação conduzida pelo particular, distante do interesse público ${ }^{27}$.

\section{CONSIDERAÇÕES FINAIS}

Agrotóxicos podem contaminar reservatórios de água, rios, recursos hídricose bacias fluviais, podendo interferir nos organismos vivos aquáticos. Algumas substâncias já proibidas há décadas no País, como é o caso do Hexaclorociclohexano $(\mathrm{HCH})$, ainda estão sendo detectadas em amostras de águas, poços e mananciais. Lagos urbanos,como um localizado na cidade de Cascavel,no Paraná, estado com intensa atividade agrícola,apresentaram contaminação recente por organofosforados. Situação semelhante foi encontrada em Fortaleza, onde foram detectadas as substâncias cipermetrina e malationa em dois rios da região metropolitana. Até mesmo na água da chuva, em regiões de produção de soja, foi detectada a presença de diferentes agrotóxicos ${ }^{28}$.

Caso aprovado, o PL n ${ }^{\circ}$ 6.299/2002 permitirá o registro de produtos mais tóxicos que os já registrados no país, bem como o registro de produtos com potencial nocividade ao meio ambiente e ao homem. Além disso, também restringe a divulgação das pesquisas de monitoramento de resíduos de agrotóxicos em alimentos, impedindo a população de ter conhecimento sobre o que está nos alimentos que consome.

A Constituição Federal de 1988 define ainda a alimentação como um dos direitos sociais assegurados no Brasil. Este direito está diretamente expresso na definição de segurança alimentar e nutricional, formalmente colocada pela Lei Orgânica de Segurança Alimentar e Nutricional (LOSAN), Lei n 11.346/2006, que orienta a atuação do Conselho Nacional de Segurança Alimentar e

\footnotetext{
${ }^{27}$ BRASIL. Instituto brasileiro do meio ambiente e dos recursos naturais renováveis - Ibama. Nota técnica $\quad \mathrm{n}^{\circ} \quad 4 / 2018 /$ DIQUA. Disponivel em: http://www.ibama.gov.br/phocadownload/noticias/noticias2018/SEI_02000.000406_2016_93.pd f. Acesso em 26.07.2019.

${ }^{28}$ LOPES, Carla Vanessa Alves; ALBUQUERQUER, Guilherme Souza Cavalcanti. Agrotóxicos e seus impactos na saúde humana e ambiental: uma revisão sistemática. Saúde Debate, Rio de Janeiro, vol. 42, n 117, abr.-jun, 2018, p. 522.
} 
Nutricional (Consea), órgão de assessoramento imediato da Presidência da República. Nos termos da LOSAN, a segurança alimentar e nutricional consiste na realização do direito de todos ao acesso regular e permanente a alimentos de qualidade, em quantidade suficiente, sem comprometer o acesso a outras necessidades essenciais, tendo como base práticas alimentares promotoras da saúde, que respeitem a diversidade cultural e que sejam ambiental, cultural, econômica e socialmente sustentáveis.

O modelo de produção e consumo de alimentos é fundamental para garantia de segurança alimentar e nutricional, pois, para além da fome, há insegurança alimentar e nutricional sempre que são produzidos alimentos sem respeito ao ambiente, com uso de agrotóxicos que afetam a saúde de trabalhadores e consumidores, sem respeito aos princípios da vedação do retrocesso socioambiental, da prevenção e da precaução, ou, ainda, quando há ações, incluindo publicitárias, que levam ao consumo de alimentos que fazem mal a saúde.

Além da inconstitucionalidade patente do PL do Veneno (embora o Supremo Tribunal Federal, ao analisar o novo Código Florestal, mudou a regra básica de que ato ilícito não é gerador de direito e de que não se retrocede em matéria socioambiental), o risco às presentes e futuras gerações revela-se imediato, lembrando que, apenas em 2019, 239 novos agrotóxicos foram autorizados pelo governo brasileiro, mesmo sob a atual e menos branda legislação se comparada com o texto do $\mathrm{PL}^{29}$.

${ }^{29} \mathrm{G} 1$. Governo federal libera mais 42 agrotóxicos no Brasil e amplia recorde desde a posse de Bolsonaro.

Disponível em: http://oglobo.globo.com/sociedade/governo-federal-libera-mais-42-agrotoxicosno-brasil-amplia-recorde-desde-posse-de-bolsonaro-23760869. Acesso em: 25 jul. 2019. 
A contaminação de cursos d'água, mesmo distantes de zonas de plantio, os malefícios à saúde de trabalhadores e consumidores ${ }^{30}$ e o cenário de negação da promoção da proteção ambiental são os principais, porém não correspondem ao todo dos efeitos nocivos da autorização e emprego desenfreado de agrotóxicos. O estudo de caso que iniciou este trabalho comprovou, talvez pela primeira vez no Estado brasileiro, que o abuso nas práticas de plantio, manejo e controle cometido pelo agronegócio passou a impactar, até mesmo, o próprio agronegócio em determinados cultivos, causando quebra na safra com qualidade e quantidade inferiores de produção.

A literatura sobre o tema traz importantes contribuições da produção científica sobre os impactos deletérios do uso de agrotóxicos sobre o ambiente e a saúde humana e acerca do precário monitoramento dos agrotóxicos, desde o pedido de autorização à destinação final das embalagens vazias pelo consumidor final. Percebe-se importante lacuna no que diz respeito ao desvelamento dos nexos dos processos atinentes aos níveis singular, particular e estrutural da cadeia, na determinação da saúde e de doenças ligadas ao uso dos agrotóxicos. Analisar apenas os processos singulares e particulares de determinação da saúde é insuficiente para a ação efetiva de prevenção. Desmontar o sistema tripartite, desvincular do parecer técnico e empregar figuras como registro temporário constitui uma fiscalização apenas formal, distante da material, de novos agrotóxicos que serão empregados no campo para chegar fatalmente ao meio ambiente, ao organismo dos trabalhadores e à mesa dos consumidores.

\section{REFERÊNCIAS:}

\footnotetext{
${ }^{30}$ Um júri dos Estados Unidos condenou nesta segunda-feira (13) a Monsanto, que pertence ao grupo alemão Bayer, a pagar US $\$ 2$ bilhões a um casal de americanos que teve câncer atribuído ao agrotóxico Roundup, informaram os advogados das vítimas. A indenização de US\$ 2 bilhões - US\$ 1 bi por cônjuge - se soma a outros US\$ 55 milhões concedidos a Alberta e Alva Pilliod por despesas, danos morais e outros. A ação corria em um tribunal de Oakland, no oeste do país. O Roundup é um produto elaborado à base de glifosato, um polêmico princípio ativo de herbicidas alvo de milhares de ações que correm atualmente nos tribunais dos EUA. G1. Monsanto é condenada a pagar US\$ 2 bilhões por agrotóxico Roundup, à base de glifosato. Disponível em: http://g1.globo.com/economia/agronegocios/noticia/2019/05/14/monsanto-econdenada-pela-3a-vez-a-indenizacao-bilionaria-por-agrotoxico-roundup-a-base-deglifosato.ghtml. Acesso em 25 jul. 2019.
} 
BECK, Ulrich. Sociedade de risco: rumo a uma outra modernidade. Tradução de Sebastião Nascimento. São Paulo: Ed. 34, 2011.

BERCOVICl, Gilberto. Constituição econômica e desenvolvimento: uma leitura a partir da Constituição de 1988. São Paulo: Malheiros Editores, 2005.

BRASIL. Agência Nacional de Vigilância Sanitária - ANVISA. Nota Técnica $\mathrm{n}^{\circ}$ 15/2018/SEI/DICOL/ANVISA. Disponível em: http://portal.anvisa.gov.br/documents/219201/4340788/_+SEI+_+ANVISA++0202694+-+Nota+T\%C3\%A9cnica+da+Dicol+_.pdf/7af8b109-5fbe-4338b5fa-3698e513bf96. Acesso em: 26 jul. 2019.

BRASIL. Lei $n^{\circ} 7.802$, de 11 de julho de 1989. Dispõe sobre a pesquisa, a experimentação, a produção, a embalagem e rotulagem, o transporte, 0 armazenamento, a comercialização, a propaganda comercial, a utilização, a importação, a exportação, o destino final dos resíduos e embalagens, o registro, a classificação, o controle, a inspeção e a fiscalização de agrotóxicos, seus componentes e afins, e dá outras providências. Publicado no Diário Oficial da União, Brasília, 12 jul. 1989. Disponível em: http://www.planalto.gov.br/ccivil_03/leis//7802.htm. Acesso em: 29 jul. 2019.

BRASIL. Lei $n^{\circ}$ 9.974, de 06 de junho de 2000. Altera a Lei $n^{\circ} 7.802$, de 11 de julho de 1989, que dispõe sobre a pesquisa, a experimentação, a produção, a embalagem e rotulagem, o transporte, o armazenamento, a comercialização, a propaganda comercial, a utilização, a importação, a exportação, o destino final dos resíduos e embalagens, o registro, a classificação, o controle, a inspeção e a fiscalização de agrotóxicos, seus componentes e afins, e dá outras providências. Publicado no Diário Oficial da União, Brasília, 07 jun. 2000. Disponível em: http://www.planalto.gov.br/ccivil_03/LEIS/L9974.htm. Acesso em: 29 jul. 2019.

BRASIL. Lei $n^{\circ} 11.346$, de 15 de setembro de 2006. Cria o Sistema Nacional de Segurança Alimentar e Nutricional - SISAN com vistas em assegurar o direito humano à alimentação adequada e dá outras providências. Publicado no Diário Oficial da União, Brasília, 16 set. 2006. Disponível em: http://www.planalto.gov.br/ccivil_03/_Ato2004-2006/2006/Lei/L11346.htm. Acesso em: 29 jul. 2019.

BRASIL. Câmara dos Deputados. PL n 6.299/2002. Altera a Lei ${ }^{\circ} 7.802$, de 11 de julho de 1989, que dispõe sobre a pesquisa, a experimentação, a produção, a embalagem e a rotulagem, o transporte, o armazenamento, a comercialização, a propaganda comercial, a utilização, a importação, a exportação, o destino final dos resíduos e embalagens, o registro, a classificação, o controle, a inspeção e a fiscalização de agrotóxicos, seus componentes e afins, e dá outras providências. Disponível em: http://www.camara.leg.br/proposicoesWeb/fichadetramitacao?idProposicao=46 249. Acesso em: 29 jul. 2019. 
BRASIL. Câmara dos Deputados. Comissão especial aprova parecer que muda legislação brasileira sobre agrotóxicos. Disponível em: http://www2.camara.leg.br/camaranoticias/noticias/AGROPECUARIA/559559COMISSAO-ESPECIAL-APROVA-PARECER-QUE-MUDA-LEGISLACAOBRASILEIRA-SOBRE-AGROTOXICOS.html. Acesso em: 20 jul. 2019.

BRASIL. Constituição da República Federativa do Brasil de 1988. Publicado no Diário Oficial da União, Brasília, 05 out. 1988. Disponível em: http://www.planalto.gov.br/ccivil_03/constituicao/constituicao.htm. Acesso em: 28 jun. 2019.

BRASIL. Decreto $n^{\circ} 4.074$, de 04 de janeiro de 2002. Regulamenta a Lei no 7.802, de 11 de julho de 1989, que dispõe sobre a pesquisa, a experimentação, a produção, a embalagem e rotulagem, o transporte, 0 armazenamento, a comercialização, a propaganda comercial, a utilização, a importação, a exportação, o destino final dos resíduos e embalagens, o registro, a classificação, o controle, a inspeção e a fiscalização de agrotóxicos, seus componentes e afins, e dá outras providências. Publicado no Diário Oficial da União, Brasília, 05 jan. 2002. Disponível em: http://www.planalto.gov.br/ccivil_03/LEIS/L9974.htm. Acesso em: 29 jul. 2019.

BRASIL. Ministério da Saúde. Fiocruz divulga nota técnica contra projeto que flexibiliza regulação de agrotóxicos. Disponível em: http://portal.fiocruz.br/sites/portal.fiocruz.br/files/documentos/nota_tecnica_pl_a gratoxicos.pdf. Acesso em: 27 jul. 2019.

BRASIL. Instituto Brasileiro do Meio Ambiente e dos Recursos Naturais Renováveis - Ibama. Nota técnica $n^{\circ}$ 4/2018/DIQUA. Disponível em: http://www.ibama.gov.br/phocadownload/notas/2018/nota_tecnica_4_2018_diq ua.pdf. Acesso em: 26 jul. 2019.

CANOTILHO, Joaquim José Gomes. Estado de Direito. Cadernos Democráticos, n 7. Fundação Mário Soares, Lisboa: Gradiva, 1998.

DW BRASIL. Brasil ainda usa agrotóxicos já proibidos em outros países. Disponível em: http://www.dw.com/pt-br/brasil-ainda-usa-agrot\%C3\%B3xicosj\%C3\%A1-proibidos-em-outros-pa\%C3\%ADses/a-18837979. Acesso em: 20 jul. 2019.

G1. Governo federal libera mais 42 agrotóxicos no Brasil e amplia recorde desde a posse de Bolsonaro.

Disponível em: http://oglobo.globo.com/sociedade/governo-federal-libera-mais42-agrotoxicos-no-brasil-amplia-recorde-desde-posse-de-bolsonaro-23760869. Acesso em: 25 jul. 2019. 
G1. Monsanto é condenada a pagar US\$ 2 bilhões por agrotóxico Roundup, à base de glifosato. Disponível em: http://g1.globo.com/economia/agronegocios/noticia/2019/05/14/monsanto-econdenada-pela-3a-vez-a-indenizacao-bilionaria-por-agrotoxico-roundup-abase-de-glifosato.ghtml. Acesso em 25 jul. 2019.

LOPES, Carla Vanessa Alves; ALBUQUERQUER, Guilherme Souza Cavalcanti. Agrotóxicos e seus impactos na saúde humana e ambiental: uma revisão sistemática. Saúde Debate, Rio de Janeiro, vol. 42, nº 117, p. 518-534, Abr.-jun, 2018.

MILARÉ, Édis. Direito do ambiente. 4 ed. São Paulo: Revista dos Tribunais, 2005.

MILARÉ, Édis. Direito do ambiente: a gestão ambiental em foco - doutrina, jurisprudência, glossário. São Paulo: Revista dos Tribunais, 2009.

MOLINARO, Carlos Alberto. Direito ambiental: proibição de retrocesso. Porto Alegre: Livraria do Advogado, 2007.

NOVAIS, Jorge Reis. Direitos fundamentais: trunfos contra a maioria. Coimbra: Coimbra Editora, 2006.

OLIVEIRA JÚNIOR, Rubens S. et al. Efeito de subdoses de 2,4-D na produtividade de uva Itália e suscetibilidade da cultura em função de seu estágio de desenvolvimento. In: Engenharia Agrícola, Jaboticabal, vol. 27, $\mathrm{n}^{\circ}$ especial, p. 35-40, jan.- 2007.

PERES, Frederico; MOREIRA, Josino Costa; LUZ, Claudio. Os impactos dos agrotóxicos sobre a saúde e o ambiente. Ciência e saúde coletiva, Rio de Janeiro , vol. 12, $\mathrm{n}^{\circ}$ 1, p. 4, mar. 2007. Disponível em: http://www.scielo.br/scielo.php?script=sci_arttext\&pid=\$1413$81232007000100001 \&$ Ing=en\&nrm=iso. Ácesso em: 29 jul. 2019.

RIO GRANDE DO SUL. Secretaria da Agricultura, Pecuária e Desenvolvimento Rural. Instrução Normativa SEAPDR $n^{\circ}$ 05/2019. Disponível em: http://www.agricultura.rs.gov.br/agricultura-estabelece-regras-para-aplicacoesde-agrotoxicos-para-evitar-deriva. Acesso em: 20 jul. 2019.

RIO GRANDE DO SUL. Secretaria da Agricultura, Pecuária e Desenvolvimento Rural. Relatório Técnico Impacto dos herbicidas hormonais nos cultivos sensíveis a estes herbicidas (2019). Disponível em: http://estado.rs.gov.br/agricultura-apresenta-propostas-para-uso-do-herbicida2-4-d-no-rio-grande-do-sul. Acesso em: 20 jul. 2019.

SARLET, Ingo Wolfang. A eficácia dos direitos fundamentais. 10. ed. Porto Alegre: Livraria do Advogado, 2009. 
SARLET, Ingo Wolfang; FENSTERSEIFER, Tiago. Princípios do direito ambiental. São Paulo: Saraiva, 2014.

SILVA, José Afonso da. Direito ambiental constitucional. 4. ed. São Paulo: Malheiros Editores, 2003.

SILVA, José Afonso da. Direito ambiental constitucional. 6. ed. São Paulo: Malheiros Editores, 2007.

STRECK, Lênio Luiz. Jurisdição constitucional e hermenêutica: uma nova crítica do direito. 2. ed. Rio de Janeiro: Forense, 2003.

UOL. Blairo Maggi recebeu, do Greenpeace, o troféu "Motosserra de Ouro". Disponivel em: http://noticias.uol.com.br/ultnot/2005/06/20/ult1928u1185.jhtm. Acesso em: 28 jul. 2019.

VIEGAS, Eduardo. Os danos potenciais com a aprovação do PL do Veneno. Disponível em: http://www.conjur.com.br/2018-jul-21/ambiente-juridico-danospotenciais-aprovacao-pl-veneno. Acesso em: 26 jul. 2019. 